\title{
RELIABILITY OF THERMOCOUPLES IN MICROWAVE CERAMICS PROCESSING
}

Juan Aguilar, Zarel Valdez, Ubaldo Ortiz

Universidad Autónoma de Nuevo León, Facultad de Ingeniería Mecánica y Eléctrica, Apartado Postal 076 F, Cd. Universitaria, San Nicolás de los Garza, N.L. 66450, México.

\begin{abstract}
It is not rare to hear arguments against the use of thermocouples for taking temperatures in processes that are taking place under microwave fields. However, the simplicity of this device makes it attractive to consider its use. One question that arises when thermocouples are employed is if the electric field perturbs the measurement, and if the thermocouple affects the processing. The process that was chosen for conducting this test was the synthesis of spinel $\left(\mathrm{MgAl}_{2} \mathrm{O}_{4}\right)$ using microwaves as a power supply and hematite $\left(\mathrm{Fe}_{2} \mathrm{O}_{3}\right)$ as an additive for both spinel formation promotion and thermal auxiliary. The alumina-based systems are very important to study because this is one of the most common ingredients in refractory materials. There are many discussions about the improvement of the process when microwaves are used, but a kinetic comparison cannot be performed if the temperature is unknown, and that is the reason for emphasizing the measurement techniques. The analysis of the obtained samples was carried out by X-ray diffraction of powders. The results of this work show that there is no difference between the products obtained when the thermocouple was inserted in the system, compared to the processing without it; hence the thermocouple is appropriate for this application.
\end{abstract}

\section{KEY WORDS}

Spinel, hematite, microwave, thermocouple

\section{INTRODUCTION}

There are several reports of thermocouples employed for temperature measurements in a microwave field $[1,2,3]$. One of the tests for demonstrating the reliability of a thermocouple consists in heating a sample with the thermocouple placed in such a position that either the electric field is perpendicular to the thermocouple [2] or the thermocouple is protected by a shield and the sample itself. The microwave-heating device is controlled with an on/off device that allows maintaining the temperature. Because of the on/off cycle there are ripples in temperature with the frequency given by the controller. What is important here is that the line forming the ripples (cycling frequency) is continuous and does not exhibit any gap or jump when the power supply switches on. In this test, the temperature of hematite was kept at two values $\left(800^{\circ} \mathrm{C}\right.$ and $\left.1000^{\circ} \mathrm{C}\right)$. Notice that wherever or not the system is in the heating or cooling stage, the line in the cycle is continuous. In turn this also demonstrates that hematite absorbs microwaves.

Specific experiments for testing thermocouple reliability where performed at a sampling rate of 5 readings/sec. Cycling frequency is coming from the controller action (Figure 2). This test proves that the thermocouple is not being affected by the electric field, although it 
does not prove the opposite, that the electric field is not being affected by the thermocouple, or even better, that if a process is taking place it would not be affected. Reliability of the thermocouples would be confirmed with the insensitivity to switching during heating stages, and obtaining the same products as without thermocouples. The first statement has been proven, while the second requires a comparison of the obtained products. One candidate for performing this comparison is the spinel $\mathrm{MgAl}_{2} \mathrm{O}_{4}$ processed with microwaves from $\mathrm{MgO}$ and $\mathrm{Al}_{2} \mathrm{O}_{3}$ and hematite as an additive for promoting spinel formation, which has been studied previously [4].

The objective of this research is to evaluate thermocouple reliability based on the above statements.

\section{Microwave processing}

Microwave heating consists in supplying the energy to a system by means of electromagnetic waves in the range of 1 through $30 \mathrm{GHz}$. The heating mechanisms are well known, but there is still controversy regarding simultaneous contribution of each one to thermal dissipation within the material. The amount of energy dissipated depends on the intensity of the electric field in the material and its properties, mainly the loss factor. In a general way, as the loss factor is increased the capacity for absorbing energy improves. The loss factor of magnesia is very small at practically any temperature, but the absorption in alumina and spinel increase their loss factor significatively above $500^{\circ} \mathrm{C}$.

\section{$\mathrm{MgO}-\mathrm{Al}_{2} \mathrm{O}_{3}$ system and hematite $\left(\mathrm{Fe}_{2} \mathrm{O}_{3}\right)$}

Magnesia-alumina spinel $\left(\mathrm{MgAl}_{2} \mathrm{O}_{4}\right)$ is a structure that results from the reaction between magnesia $(\mathrm{MgO})$ and alumina $\left(\mathrm{Al}_{2} \mathrm{O}_{3}\right)$. Although it is thermodynamically feasible to have this spinel at a wide range of temperatures and compositions, in practice temperatures over $1200^{\circ} \mathrm{C}$ are required for producing an appreciable reaction reasonable time scales. The stoichiometric composition $\mathrm{MgO}: \mathrm{Al}_{2} \mathrm{O}_{3}$ is $1: 1$ mole. It has been discussed in other works [4] how hematite promotes the formation of $\mathrm{MgAl}_{2} \mathrm{O}_{4}$ spinel.

Hematite is a good microwave absorber, hence if it is present in the mixture, it should be able to heat the alumina to $500^{\circ} \mathrm{C}$ where alumina becomes a microwave absorber too. There are two hematite phases, the $\alpha \mathrm{Fe}_{2} \mathrm{O}_{3}$ and the $\beta \mathrm{Fe}_{2} \mathrm{O}_{3}$. The latter has a lattice structure similar to alumina's. It has been reported [5] that at temperatures between $500^{\circ} \mathrm{C}$ and $700^{\circ} \mathrm{C}$, the electron diffraction of the hematite crystal is different from those of $\alpha$ or $\gamma$ hematite, meaning that there is another phase that has been designated as $\beta \mathrm{Fe}_{2} \mathrm{O}_{3}$. It could a superstructure effect or an order-disorder reaction. In any case, this process has been reported endothermic, absorbing $160 \mathrm{cal} / \mathrm{mole}$ at $677^{\circ} \mathrm{C}$.

\section{EXPERIMENTAL PROCEDURE}

Sets of mixtures with different compositions of the system $\mathrm{MgO}-\mathrm{Al}_{2} \mathrm{O}_{3}-\mathrm{Fe}_{2} \mathrm{O}_{3}$ (high purity) were prepared. The reagents $\mathrm{MgO}$ and $\mathrm{Al}_{2} \mathrm{O}_{3}$ were mixed thoroughly to get intimate contact between the powders. The compositions are shown in Table I. The mixture ( 7 gr non compacted, approximately $10 \mathrm{~cm}^{3}$ ) was placed into a high purity alumina crucible, which was $50 \mathrm{~mm}$ outer diameter, $36 \mathrm{~mm}$ inner diameter, $35 \mathrm{~mm}$ height and $115 \mathrm{gr}$ weight. Figure 3 shows the arrangement. This crucible was placed over another upside-dawn crucible in 
order to have the mixture in a location that has been found to be the best according to previous research [6]. The thermocouple was a shielded (3.17 $\mathrm{mm}$ diameter) ungrounded type $\mathrm{K}$ placed at the center of the crucible. The whole system was insulated with ceramic fiber known as Kwool.

As was explained above, magnesia is not a good microwave absorber, and alumina begings to absorb when the temperature is above $500^{\circ} \mathrm{C}$. However, the hematite in the mixture acts as a microwave susceptor that absorbs energy at room temperature and heat up the mixture to $500^{\circ} \mathrm{C}$. At this temperature and above, alumina and the just formed spinel are able to absorb microwave energy by themselves. Following the example of previous experience with this kind of material [6], mixtures were exposed to $800 \mathrm{~W}$ at $2.45 \mathrm{GHz}$ microwave energy for 30 minutes. It was shown that the thermocouple is not affected by the electric field. By chemical analysis of the products, it is possible to determine if the thermocouple is affecting the process. With this idea, a comparison against tests without a thermocouple was also performed in order to detect possible differences. In the thermocouple case, when temperature was about to exceed $1200^{\circ} \mathrm{C}$, which is the maximum for a $\mathrm{K}$ type thermocouple, it was removed from the system, and process was allowed to continue.

\section{RESULTS AND DISCUSSION}

In figure 2 it was shown that the hematite absorbs microwaves and that the microwave field did not affect the thermocouple, which would otherwise show a non-thermal change during switching of the controller. Additional evidence on this issue was obtained from tests conducted in a mixture of $\mathrm{MgO}$ and $\mathrm{Al}_{2} \mathrm{O}_{3}(7 \mathrm{gr})$, where temperature was maintained at $1200^{\circ} \mathrm{C}$ with a set point tolerance of $10^{\circ} \mathrm{C}$, and sampling rate of 1 reading/sec (Figure 4). The same continuity can be appreciated even when the sampling time was larger. Comparing figures 2 and $4\left(50^{\circ} \mathrm{C}\right.$ and $10^{\circ} \mathrm{C}$ respectively) it can be appreciated that lower setting tolerance produces cycling frequency that is one and a half higher.

As was pointed out earlier, the purpose of this work is to show the reliability of thermocouples for measuring temperature, and to determine if they are involved in anomalies in the products. The samples were removed from the crucible and analyzed by means of powders X-Ray diffraction (cooper anode, $\lambda=1.54 \AA$ ), relative peak intensity was used for estimating amounts of each specie after calibration with specimens of known composition. Results are shown in Table III.

The maximum temperature reached was estimated to be around $2000^{\circ} \mathrm{C}$ based on two aspects: the temperature of the insulator reached by the end of the test was $2000^{\circ} \mathrm{C}$ (confirmed by optical pyrometry), and the melting point of the compounds found in this system range between $2000^{\circ} \mathrm{C}$ and $2135^{\circ} \mathrm{C}$. The samples were found to have been molten. In this case there where not parallel thermocouple - pyrometer readings because the thermocouple was inside the mixture and the insulation was outside. Therefore the temperatures would not be the same. Besides, the thermocouple could not work above $1200^{\circ} \mathrm{C}$ and the pyrometer could not measure temperature below $600^{\circ} \mathrm{C}$.

Results of tests with and without the thermocouple inserted are presented in Table II. The melting point decreases as hematite is added, therefore the mixture becomes molten and it is difficult to identify each zone into the sample. At low hematite content $(5 \%)$ it was possible to identify different portions of the sample because it was incipiently molten. The difference between the upper portion and the bottom one is due to the insulating differences. Although the system was insulated, the most insulated portion is located at the 
center bottom of the crucible, and the achieved temperature is higher in this place. It can be seen that the tests with the thermocouple and without it gave the same results, which means that the thermocouple did not affect the process. This analysis is evidence of the importance of the thermal gradient inside the sample. Indeed, this gradient is more important than the possible error introduced by the thermocouple.

The sensitivity of the thermocouples can be evaluated from the thermal evolution (Figure 5) of the three chosen hematite compositions, as it was pointed out the last point is below $1200^{\circ} \mathrm{C}$ because of the thermocouple limitations. Figure 6 shows heating slopes against temperature for different hematite contents up to pure hematite, showing in all case a dropping around $600^{\circ} \mathrm{C}$. A preliminary conclusion is that the thermocouple was sensitive enough to detect this change. From the first slope in the test of the figure 1, the heating rate was also obtained against temperature. This sample was $20 \mathrm{gr}$ of pure hematite. The thermal behavior is the same, but the heating rate is about ten times greater than in the mixtures because hematite is good microwave absorber. Dividing the heating rate by this factor made the curve to coincide in a general way with the curve of the mixtures. It is important to keep in mind that the crucible was made of alumina and that increases its absorption capacity at about $500^{\circ} \mathrm{C}$ and that the curves are affected by this fact. Despite the influence of alumina, the decreasing zone is present. The highest descent corresponds to the highest hematite content, and all of them coincided at a temperature around $650^{\circ} \mathrm{C}$. According to the description given above for the hematite transformation, which was located at $677^{\circ} \mathrm{C}$, but the same reference [5] accepts a wider range that includes the one found in this work. The important matter here is that the thermocouple was sensitive enough to follow such a thermal change.

There are not enough points at the early stage to confirm that the same changes in the slope, below $100^{\circ} \mathrm{C}$, for the 5 mole $\%$ of hematite occurs to the others. However, there is a tendency in the same sense in the $15 \%$ mole test.

\section{CONCLUSIONS}

This work was focused in two main aspects: firstly, the reliability of the thermocouples for measuring temperatures in a microwave field, and secondly, to evaluate the interference that the thermocouple has with the process itself. We have shown that for the configuration used, the field did not affect the measurements. It is clear that the field must be affected, but it does not necessarily means that the result would be also affected. Similitude in the chemical analyses with and without a thermocouple confirms that at least by the time that the thermocouple was inserted the mixture reaction profile was not altered. Moreover, the influence of the thermal gradient across the sample is by far greater than the possible effect of the thermocouple, meaning that it is possible to use thermocouples in such processes. Other thermocouples, such as the R type, resist higher temperatures (up to $1600^{\circ} \mathrm{C}$ ). If they were shielded, as was the $\mathrm{K}$ that we used, they should work the same. It is true that $2000^{\circ} \mathrm{C}$ is still too high for thermocouples, but in many cases, especially when additives or fluxes are included, such high temperatures are not required. Even the spinel $\mathrm{MgAl}_{2} \mathrm{O}_{4}$, without any additive, can be produced at $1400^{\circ} \mathrm{C}$, although longer time is necessary. In this case basic conditions, such as good shielding, good sample - thermocouple contact and a mixture that did not react to conductive products were accomplished. Attention must be paid with solid samples, species that become conductive and cavity - sample configurations that produced arcing or feedback to the magnetron. However, the thermocouple is a very 
simple device that with certain considerations can be used as a measurement probe in microwave processing.

\section{ACKNOWLEDGMENTS}

Authors express their gratitude to CONACYT (Mexican Council for Science and Technology) and PAICYT (Autonomous University of Nuevo León Research Program for Science and Technology) for their financial support.

\section{REFERENCES}

[1] J. Binner, N. Hassine, T. Cross, "The possible role of the pre-exponential factor in explaining the increased reaction rates observed during microwave synthesis of titanium carbide", Journal of Materials Science 30 (1995), pp. 5389-5393

[2] G. Roussy, J. Pearce, "Foundations and Industrial Applications of microwaves and radio frequency fields" John Wiley and Sons, (1995), pp. 237-239

[3] I. Gómez, J. Aguilar, M. González, J. Morales, "Kinetics of reduction of iron oxides using microwaves as power source" Mat. Res. Soc. Symp. Proc. 430 (1996) pp. 423-428

[4] U. Ortiz, J. Aguilar, O. Kharissova, "Effect of iron over the magnesia-alumina spinel lattice", Journal of Advances in Materials and Materials Processing, Vol. 2, No. 2, (2001) pp. 107-116.

[5] L. Bougdandy, H. Engell, "The reduction of iron ores", Springer Verlag (1971), pp. $33-35$

[6] J. Aguilar, M. González and I. Gómez, "Microwaves as an energy source for producing magnesia-alumina spinel". Journal of Microwave and Electromagnetic Energy, 32 (1997), pp. 74-79 
Table I: Compositions of the mixtures tested in this work (mole percentage)

\begin{tabular}{|c|c|c|c|}
\hline Compound/Mixture & 1 & 2 & 3 \\
\hline $\mathrm{MgO}$ & 45 & 35 & 30 \\
\hline $\mathrm{Al}_{2} \mathrm{O}_{3}$ & 50 & 50 & 50 \\
\hline $\mathrm{Fe}_{2} \mathrm{O}_{3}$ & 5 & 15 & 20 \\
\hline
\end{tabular}

Table II: Analysis of the obtained samples from the tests with and without thermocouples.

\begin{tabular}{|l|c|c|c|c|c|c|}
\hline & With & Without & With & Without & With & Without \\
\hline $\begin{array}{l}\text { Added } \mathrm{Fe}_{2} \mathrm{O}_{3} \\
\text { (Mole \%) }\end{array}$ & 5 & $\begin{array}{c}5 \\
\text { Average } \\
\text { d }\end{array}$ & 15 & $\begin{array}{c}15 \\
\text { Mixed }\end{array}$ & 20 & $\begin{array}{c}20 \\
\text { Mixed }\end{array}$ \\
\hline $\mathrm{MgO}$ & 22 & 23 & 4 & 2 & 2 & 0 \\
\hline $\mathrm{Al}_{2} \mathrm{O}_{3}$ & 14 & 15 & 2 & 0 & 0 & 0 \\
\hline $\mathrm{MgAl}_{2} \mathrm{O}_{4}$ & 28 & 37 & 47 & 49 & 0 & 0 \\
\hline $\mathrm{Mg}_{2}(\mathrm{Al}, \mathrm{Fe})_{2} \mathrm{O}_{4}$ & 30 & 18 & 36 & 38 & 98 & 93 \\
\hline $\mathrm{FeAl}_{2} \mathrm{O}_{4}$ & 6 & 6 & 11 & 11 & 0 & 7 \\
\hline
\end{tabular}

Table III: Analysis of the sample with 5 mole $\%$ of hematite at different locations, without thermocouple.

\begin{tabular}{|l|c|c|}
\hline & Upper & Bottom \\
\hline $\mathrm{MgO}($ Mole \%) & 32 & 14 \\
\hline $\mathrm{Al}_{2} \mathrm{O}_{3}($ Mole \%) & 20 & 10 \\
\hline $\mathrm{MgAl}_{2} \mathrm{O}_{4}(\mathrm{Mole} \%)$ & 33 & 42 \\
\hline $\mathrm{Mg}(\mathrm{Al}, \mathrm{Fe})_{2} \mathrm{O}_{4}$ & 9 & 28 \\
\hline $\mathrm{FeAl}_{2} \mathrm{O}_{4}$ & 6 & 6 \\
\hline
\end{tabular}




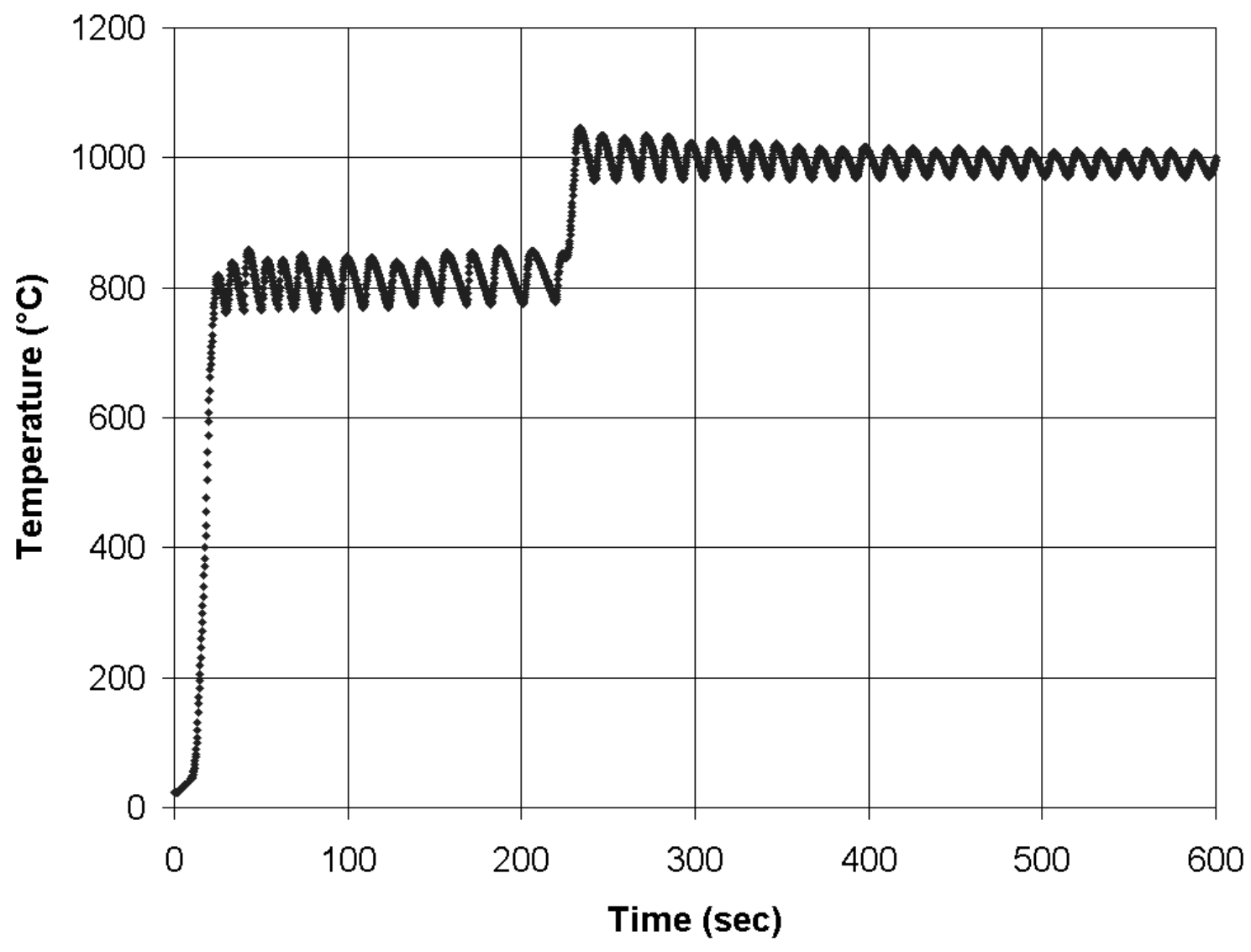

Figure 1: Test of 20 gr of hematite heated with microwaves at $2.45 \mathrm{GHz}$ and $800 \mathrm{Watts}$ in a multimode cavity. Notice the continuous ripples within the two chosen control temperatures $\left(800^{\circ} \mathrm{C}\right.$ and $\left.1000^{\circ} \mathrm{C}\right)$. 


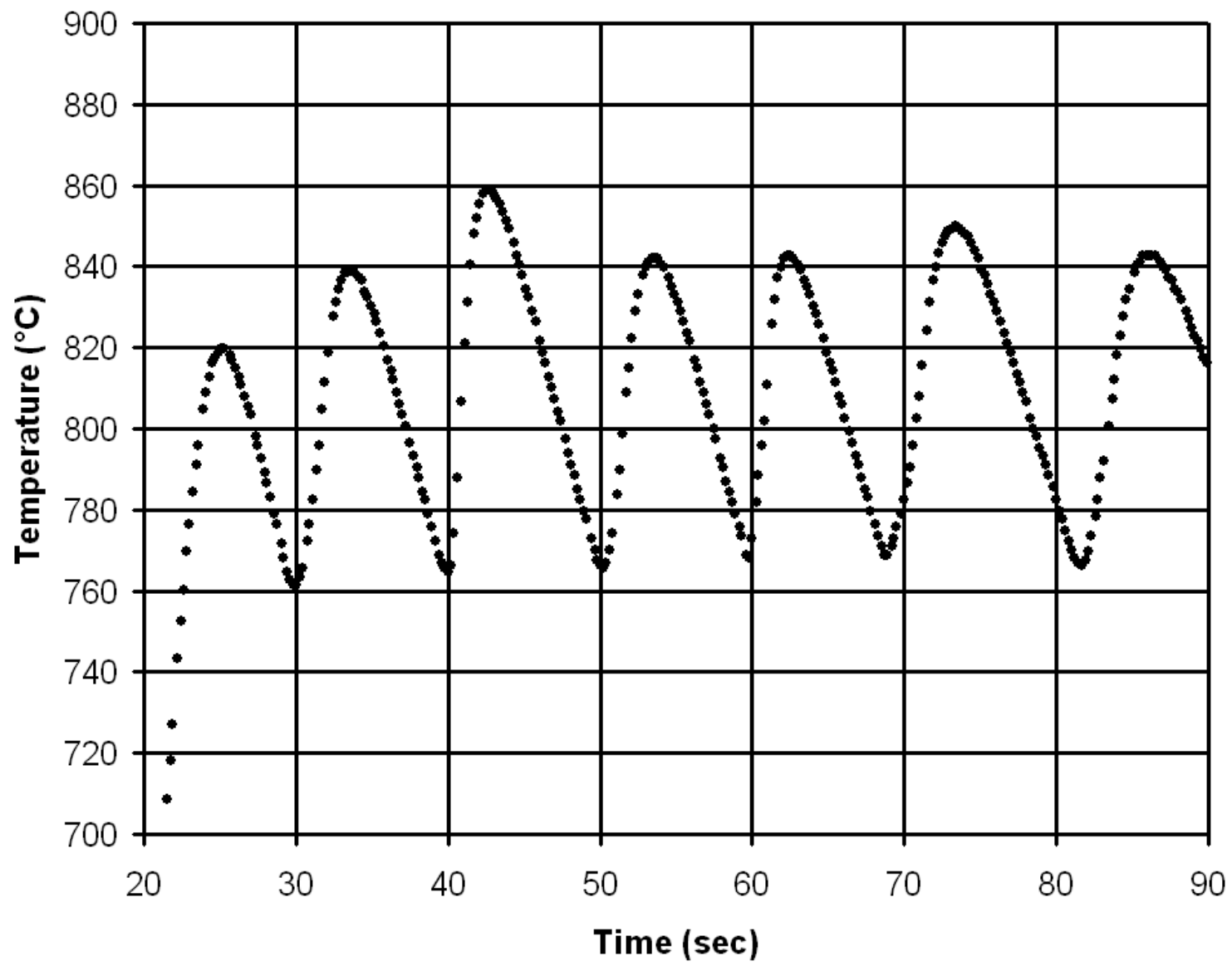

Figure 2: Section of the test of Figure 1: Notice that the continuous ripples are due to the control action. 


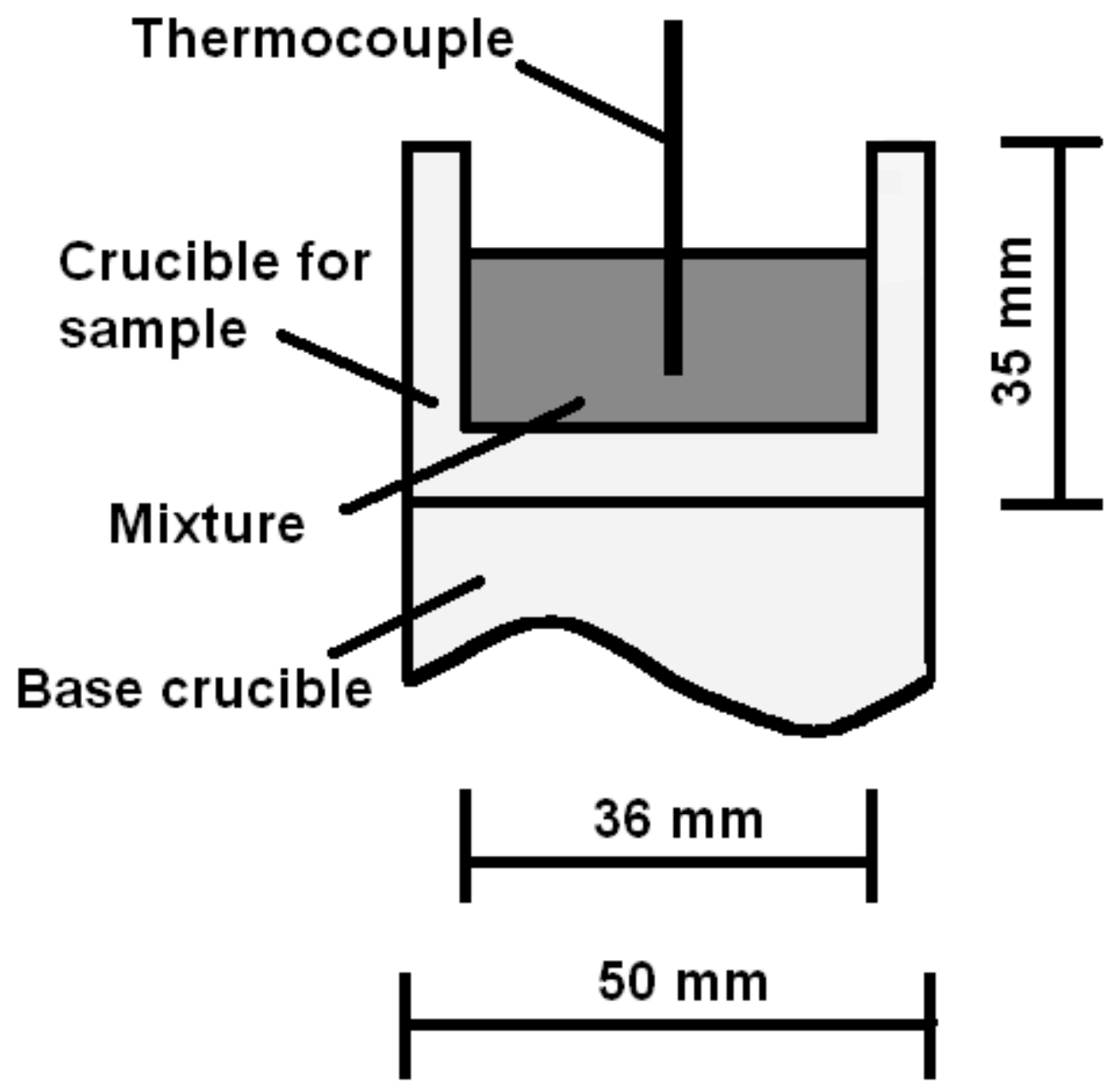

Figure 3: Drawing of the crucible and the thermocouple inserted in the mixture. 


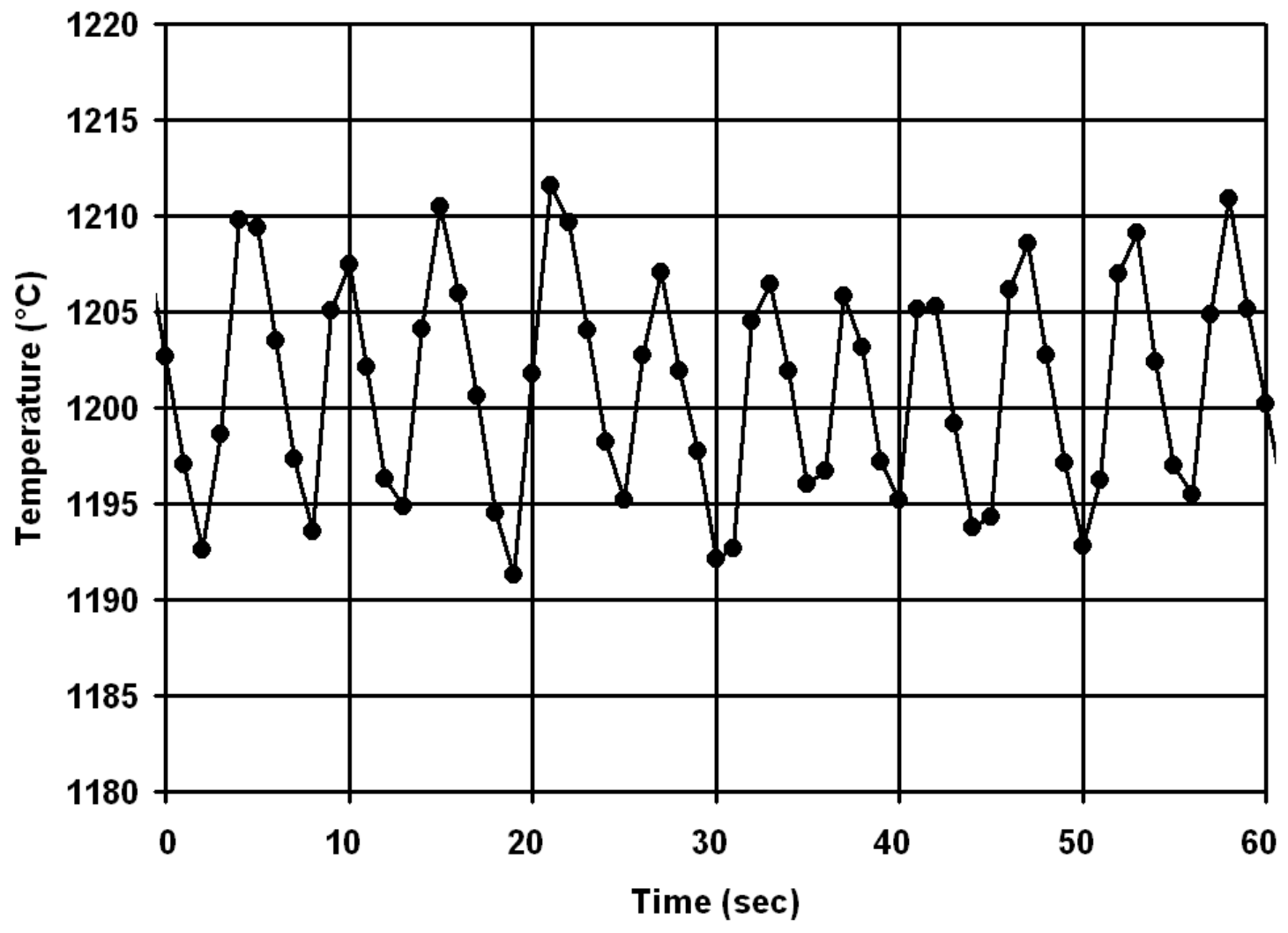

Figure 4: Test of 7 gr of $\mathrm{MgO}$ and $\mathrm{Al}_{2} \mathrm{O}_{3}$ heated with microwaves at $2.45 \mathrm{GHz}$ and 800 Watts kept at $1200^{\circ} \mathrm{C}$. 


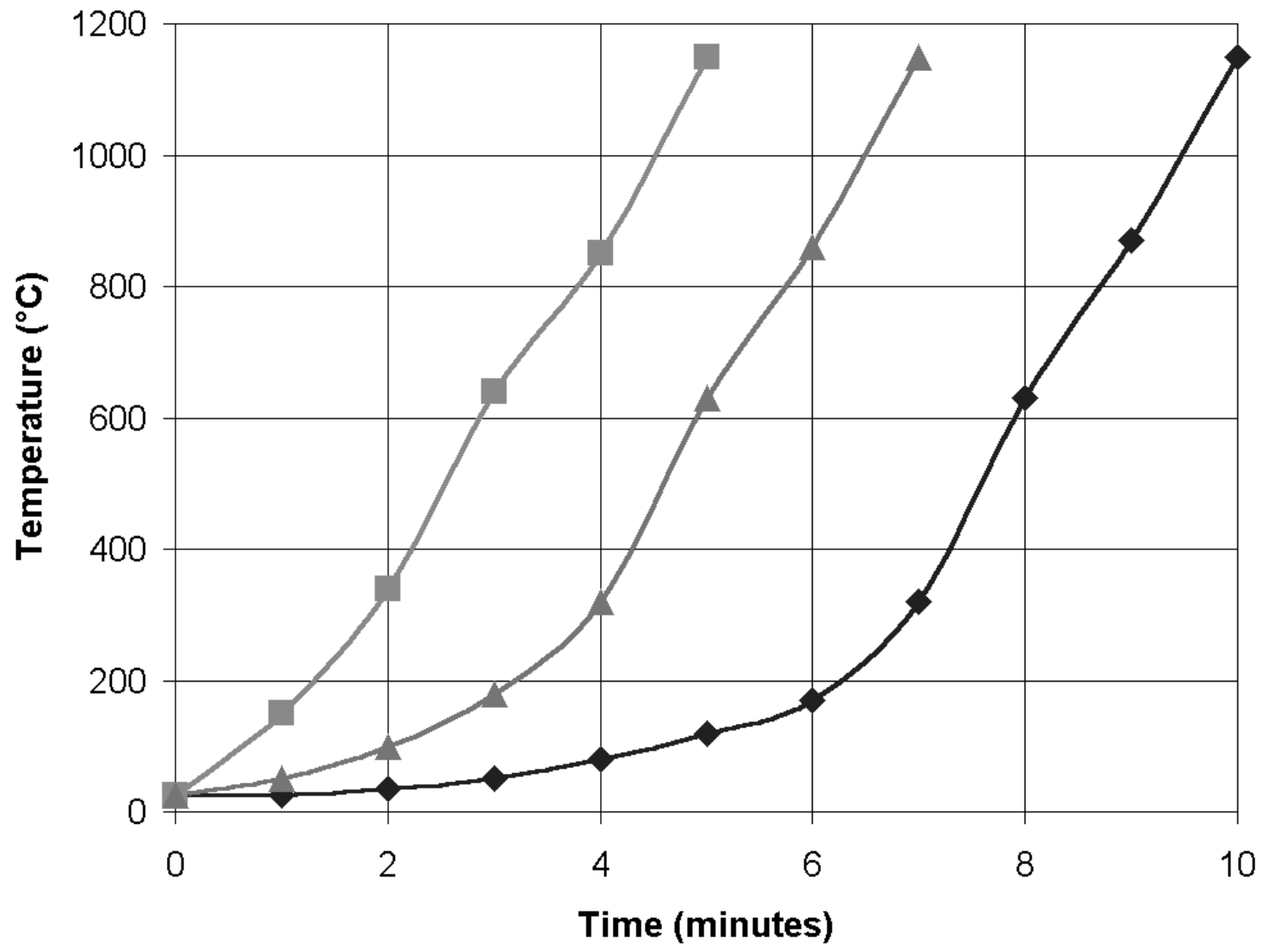

Figure 5: Heating evolution of mixtures with different hematite content: 20 mole\% (square), $15 \mathrm{~mole} \%$ (triangle) and $5 \mathrm{~mole} \%$ (diamond). 


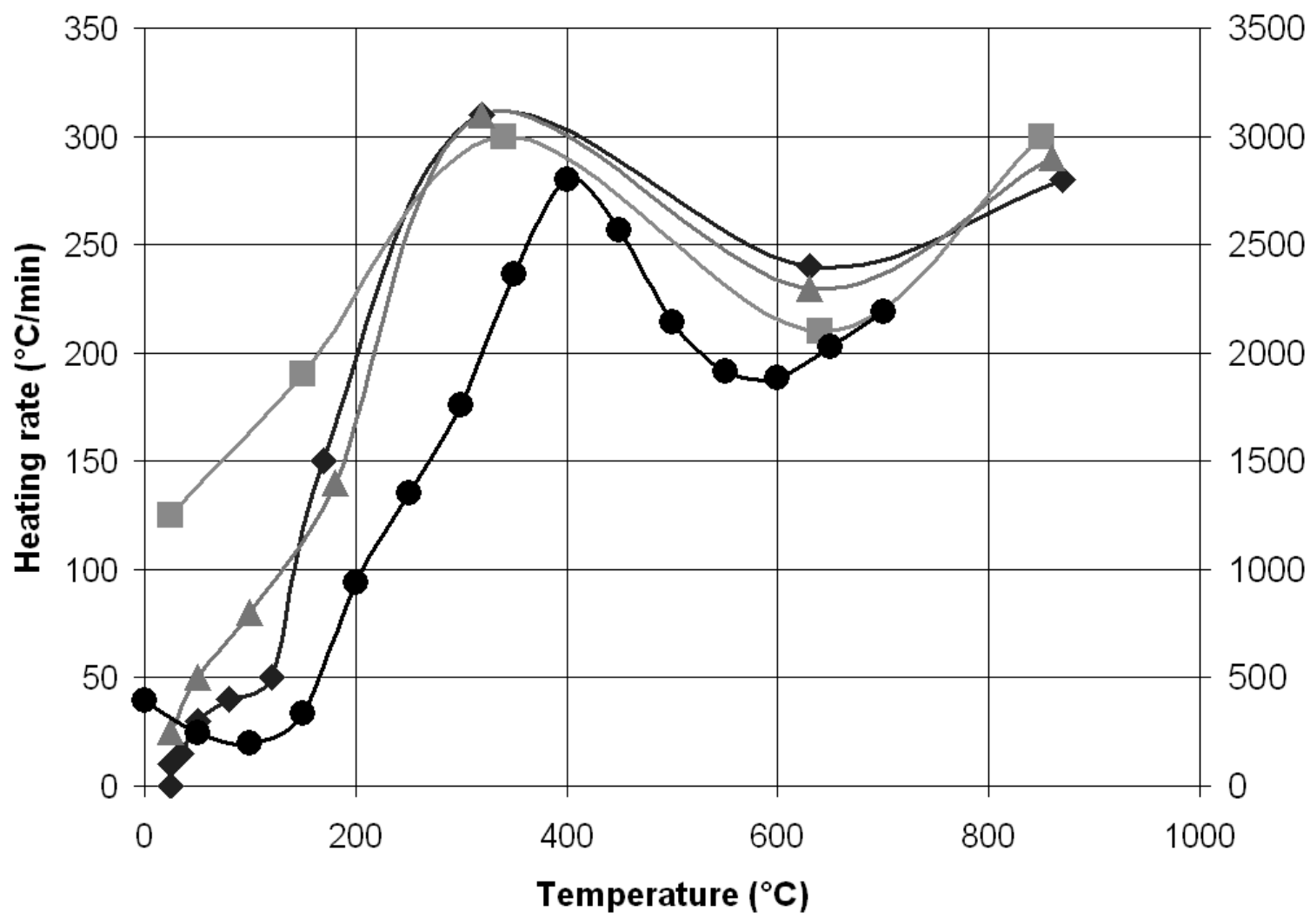

Figure 6: Heating rates for the tests of the figure 6, as function of temperature. The hematite content are: 20 mole\% (square), 15 mole\% (triangle) and 5 mole\% (diamond). The right scale is only for the hematite (dots), notice that the decreasing temperature is within the same range than in the mixtures. 